\title{
Effects of a health education intervention on hypertension-related knowledge, prevention and self-care practices in Nigerian retirees: a quasi-experimental study
}

Eyuche L. Ozoemena', Cylia N. Iweama', Olaoluwa S. Agbaje ${ }^{1 *}$, Prince C. I. Umoke ${ }^{1}$, Osmond C. Ene', Perpetua C. Ofili', Benedicta N. Agu ${ }^{2}$, Charity U. Orisa ${ }^{3}$, Michael Agu ${ }^{1}$ and Enejoh Anthony ${ }^{1}$

\begin{abstract}
Background: Education is vital to increasing knowledge, improving prevention and self-care practices for hypertension in older adults. This study aimed to determine the effectiveness of a health education intervention in improving hypertension (HT) knowledge, prevention and self-care practices among retirees in Enugu State, Southeast, Nigeria.

Methods: In this quasi-experimental study, we enrolled 400 participants in Enugu and Nsukka cities in Enugu State, south-east Nigeria. Participants were assigned to the treatment and control groups. Participants in the intervention/ treatment group (T-group) received the intervention provided by public health experts and nurses and participants in the control group (C-group) received health talk without the intervention. Data collected at baseline (before intervention), 16 weeks (4th month) and follow-up (5th month) included demographic variables, knowledge about hypertension, prevention and self-care practices. We used paired samples $t$-test, Chi-square test and one-way ANOVA repeated measures for data analyses.

Results: The mean age of the participants was 65.9 ( \pm 8.9) years, the mean SBP and DBP were $136.5( \pm 13.3)$ and 87.9 ( \pm 9.1) respectively. More than half of the participants were $(50.3 \%)$ were males, and the mean BMI was $23.9( \pm$ $5.1) \mathrm{kg} / \mathrm{m}^{2}$. The paired comparison analysis showed that the mean HT knowledge score significantly increased in the T-group between baseline and 1 month (4th month) post-intervention compared to those in the C-group $(P<$ 0.0001). Also, $P A(P=0.007)$, sleep pattern and quality $(P=0.003)$, substance use abstinence $(P=0.000)$, healthy diet $(P=0.000)$, and medication adherence $(P=0.000)$ improved significantly in the T-group compared to the control between baseline and 1 month after intervention. The repeated measures analyses showed statistically significant effects (between-groups analysis) for all outcomes with small to large effect sizes. Similarly, the repeated measures ANOVA analyses showed significant time-by-group interaction effects (within-groups) for all the outcomes with small to large effect sizes.
\end{abstract}

Conclusion: Community-based health education intervention targeted at older adults can increase HT knowledge, improve prevention and self-care practices of hypertension at the population level.

Keywords: Hypertension, Intervention, Health education, Knowledge, Prevention, Self-care

\footnotetext{
*Correspondence: agbajesam@yahoo.com; samson.agbaje@unn.edu

'Department of Human Kinetics and Health Education, Faculty of Education,

University of Nigeria, Nsukka, Enugu State, Nigeria

Full list of author information is available at the end of the article
}

(c) The Author(s). 2019 Open Access This article is distributed under the terms of the Creative Commons Attribution 4.0 International License (http://creativecommons.org/licenses/by/4.0/), which permits unrestricted use, distribution, and reproduction in any medium, provided you give appropriate credit to the original author(s) and the source, provide a link to the Creative Commons license, and indicate if changes were made. The Creative Commons Public Domain Dedication waiver (http://creativecommons.org/publicdomain/zero/1.0/) applies to the data made available in this article, unless otherwise stated. 


\section{Background}

Hypertension is a major modifiable risk factor for cardiovascular disease (CVD) and premature mortality globally [1-3]. Hypertension (HT) contributes to the burden of heart disease, stroke, kidney failure, premature mortality, and disability. Considerable evidence from observational studies has revealed strong, positive relationships between hypertension and risk of CVD and mortality $[3,4]$. It is predominantly prevalent among diverse populations in developing nations where the health systems are weak [5]. It is estimated that hypertension affects about 1 billion people globally $[6,7]$. The prevalence of hypertension is highest in the African Region at $46 \%$ of adults aged 25 years and above, while the lowest prevalence at $35 \%$ is found in the Americas [5].

Nigeria is the most populous country in Africa with an estimated population of 191 million (51\% male, 49\% female) with an estimated growth rate of $2.43 \%$ per annum and a high dependency ratio of $88 \%$ [8]. Due to this vast population, Nigeria immensely contributes to the total burden of hypertension in the continent $[6,9,10]$. . The prevalence of hypertension in the adult population in Nigeria is increasing, although, the prevalence rate varies yearly and regionally [11-13]. For instance, a number of systematic reviews and meta-analysis conducted by Adeloye et al. [6] showed an estimated overall hypertension prevalence of $28.9 \%$ while Akinlua et al. [11] and Ogah et al. [13] reported that HBP prevalence ranged from 2.1 to $47.2 \%$, and $8-46.4 \%$ in adults respectively.

Research has indicated that hypertension is more prevalent among the elderly population due to its higher prevalence and associated morbidity and mortality in this age group [3]. The poor health outcomes associated with uncontrolled hypertension include stroke, dementia, heart failure, myocardial infarction and renal failure [14]. Advancing age, an unmodifiable risk factor for high blood pressure (HBP) or hypertension has been linked with a progressive increase in the risk of vascular mortality with a $20 \mathrm{mmHg}$ rise in SBP above $125 \mathrm{mmHg}$ or $10 \mathrm{mmHg}$ above DBP of $75 \mathrm{mmHg}$ [3, 15]. Also, demographic characteristics and lifestyle factors such as gender, family history of CVD, unhealthy food intake, physical inactivity, tobacco and alcohol use, abnormal serum lipids and lipoproteins, obesity, chronic stress, and insufficient sleep are also strong risk factors for hypertension in adult populations [16-18].

However, evidence suggests $[19,20]$ that most individuals suffering from hypertension, especially the elderly are unaware of its presence, thereby increasing the occurrence of associated complications. Knowledge or awareness of hypertension is a strong predictor of prevention practices, treatment and medication adherence among hypertension patients [21-23]. A Nigerian study reported that only about $30 \%$ of hypertensive patients was aware of their condition at the time of diagnosis [24]. Also, prevention of hypertension and its comorbid conditions, modifications in medication adherence, lifestyle changes that depend on an in-depth comprehension of knowledge-based awareness have been suggested in literature [22]. Effective control of hypertension through valid health interventions has been shown to decrease the risk of cardiovascular complications especially that of systolic blood pressure (SBP) which is more prevalent among the elderly population $[14,19,25]$. In addition, effective self-care behavior or practice can facilitate cut back cardiovascular disease complications, however the speed of engagement in self-care practice is comparatively low among older patients including retirees [26].

Hence, it is imperative to evaluate the effectiveness of a community-based health education intervention on improving the HT knowledge, prevention and self-care practices of retirees in Enugu, south-east Nigeria. Studies have shown that older adults including retirees constitute a high-risk group for hypertension [3, 15-18]. The transition to retirement has been identified as important phase of life [27].. Van Dyck et al. [27] further opined that early retirement offers chances to imbibe a healthy lifestyle, and new habits can be developed by retirees due to available ample time previously spent working [28]. Also, literature suggests that retirees appear to be receptive to behavioural change [29].

Implementing an effective community-based educational intervention to improve knowledge and prevention of risk factors becomes necessary [30]. To our knowledge, no previous community-based HT education programme evaluation is reported for retirees in Enugu, south-east Nigeria. Hence, we hypothesized that a well-designed, validated, and culturally contextualized community-based health education intervention targeting retirees could lead to increased knowledge, improved HT prevention and self-care practices in the treatment group relative to the control group.

\section{Materials and methods Study design, setting and population}

This study was a community-based quasi-experimental conducted from June to November 2018 in Nsukka and Enugu, Enugu State. According to the national census of 2006, the estimated population of Enugu state was $3,267,837$. It comprised 1,596,042 males and 1,671,795 females [31]. The state has 18 Local Government Areas (LGAs) while Enugu is the central city. At the time of the study, 9613 retirees had fulfilled the mandatory 35 years in public service or attained the retirement age of 60 years as stipulated by Enugu State Civil Service Commission [32, 33]. The retirees are members of the Nigeria Union of Pensioners (NUP) and registered with the Enugu State Ministry of Finance. 


\section{Sample size and determination procedure}

This quasi-experimental study aimed at evaluating the effectiveness of health education intervention in increasing the HT knowledge, prevention and self-care practices among retirees as primary outcome variables. We calculated the study sample size based on a comparison of two independent means formula with an effect size of 0.33 and a standard deviation of 3.0. We set the level of significance at $p<0.05$, and the study power was assumed to be $80 \%$ [34]. As a result, the estimated sample size was 286 participants (i.e., $n_{1}=143, n_{2}=143$ ). Since multivariable analyses were conducted for body mass index (BMI), BP levels, HT knowledge, prevention and self-care practices, other sociodemographic variables, and considering the possibility of respondents' drop-outs, we decided to increase the number of study participants $40 \%$ more than the estimated sample size [35]. As a result, the calculated sample size was $286+$ $114=400$. Thus, we selected 400 subjects for the study. We used a two-stage sampling procedure for sample selection. We purposively selected three pension zones with the highest number of retirees in Enugu State at the time of the study [33] to enhance representativeness. These comprised Enugu $(n=6363)$, Abakpa $(n=1228)$, and Nsukka $(n=1137)$. Convenience sampling was used to select the study subjects. Subsequently, we randomly assigned 200 subjects each to the experimental group $\left(n_{1}=200\right)$ and control group $\left(n_{2}=200\right)$. The experimental or treatment and control groups consisted of 100 each of men and women. The treatment and control groups were located in Enugu and Nsukka respectively to avoid contamination. We estimated the statistical power using the G*Power 3.1.9.2 software version developed by Faul et al. [34]. We employed the priori power analysis for the difference between two independent means (two groups) procedure. We used the conventional value of $\alpha=0.05$ as indicated by Hickey et al. [35]. The results of statistical power analysis showed that the critical $\mathrm{z}=1.96835$, corresponding to $\alpha=\beta=0.8020829$ (Additional file 1). The results showed that the minimum sample size was enough for the study. The inclusion criteria included retirees aged $\geq 60$ years who gave informed consent and located within the selected zones. We excluded retirees who were ill prior to the study and those who declined participation.

\section{Recruitment and data collection}

We requested the leaders/chairpersons of the retirees in the selected pension zones to inform their colleagues about our study, rationale for the study and need for their involvement in the study. However, we emphasized voluntary participation by the retirees. Subsequently, we agreed on a specified date and time based on mutual consent. The leaders selected the weekly meeting days.
When we arrived at the designated/specified venues, the leaders introduced the principal investigators and other research assistants to the retirees. Thereafter, we explained the details of our research, and asked if they agreed to participate in the study. All the retirees present at the venues agreed to participate in the study. Next, we gave the retirees a brief on the educational programme and administered the pre-test. The data collection process was conducted in Enugu and Nsukka venues.

\section{Educational intervention}

We developed the health education intervention or programme to be culturally relevant. The health education programme on HT was developed based on the implementation research framework, the information-motivation-behavioral skills (IMB) model proposed by Fisher and Fisher [36]. The IMB model recognizes three fundamental contributing factors of the initiation and maintenance of health behaviors: accurate information that can be readily translated into health behavior performance; personal and social motivation to act on such information; and activity skills to carry out the health behavior positively and successfully. The IMB model explained the modifiable risk factors of HT such as behavior-related information and knowledge, beliefs and attitudes towards a particular health behavior and perceived social support, self-efficacy, and skills to negotiate preventive behaviors. To our knowledge, no published health education intervention on HT has used the IMB model to inform its design, content, content delivery, implementation and assessment of intervention effectiveness among older adults in south-east, Nigeria. We used a written script to standardize the contents of the intervention that included the meaning of hypertension, causes and risk factors for HT, signs and symptoms, measurement of BP and its interpretation, HT prevention, and self-care practices, and treatment and BP control. The themes of the 12-session intervention were designed based on the major topics. We conducted the sessions on the day of the week (Tuesdays for the intervention group and Thursdays for the control group) at a time the participants had considered the most convenient. The intervention lasted for 12 weeks (July to September, 2018), and each session lasted for about 60 min per week. We organized the sessions in groups of 50 retirees in both the intervention and control groups. The contents and educational materials used for the intervention were guided by the previous studies [37-42]. Health education experts and nurses delivered the contents of the educational programme to the treatment group retirees. The intervention materials included educational booklet on HT, videos, annotated charts and discussions covered all the topics. The videos were 
shown using a laptop and projector. The videos and annotated charts made it easier for those who were not strong in health literacy to understand the contents. This assisted the presenter to be consistent and provide detailed information. After each session, we gave a timeframe of $5 \mathrm{~min}$ for participants to ask questions. Correctness of the responses and answers to the questions raised by participants were validated by the health education experts and nurses. However, when questions asked by participants are outside the scope of the intervention materials, we counseled them to seek medical expertise. Also, the control group received health talk about HT and did not receive any intervention. Each session in the control group lasted for about $45 \mathrm{~min}$.
Only the health education experts delivered the health talk to the control group. We gave light refreshments (snacks and soft drinks) to the participants at the end of each session. We evaluated the HT knowledge, prevention and self-care practices of retirees in the intervention and control groups at the 4th and 5th months after the intervention (Fig. 1).

\section{Outcome variables}

We used a four-part questionnaire based on the literature to collect data on participants' demographic characteristics (age, gender, and level of education), and measure the HT knowledge [37-39], prevention, and self-care practices. We collected data in four steps. First,

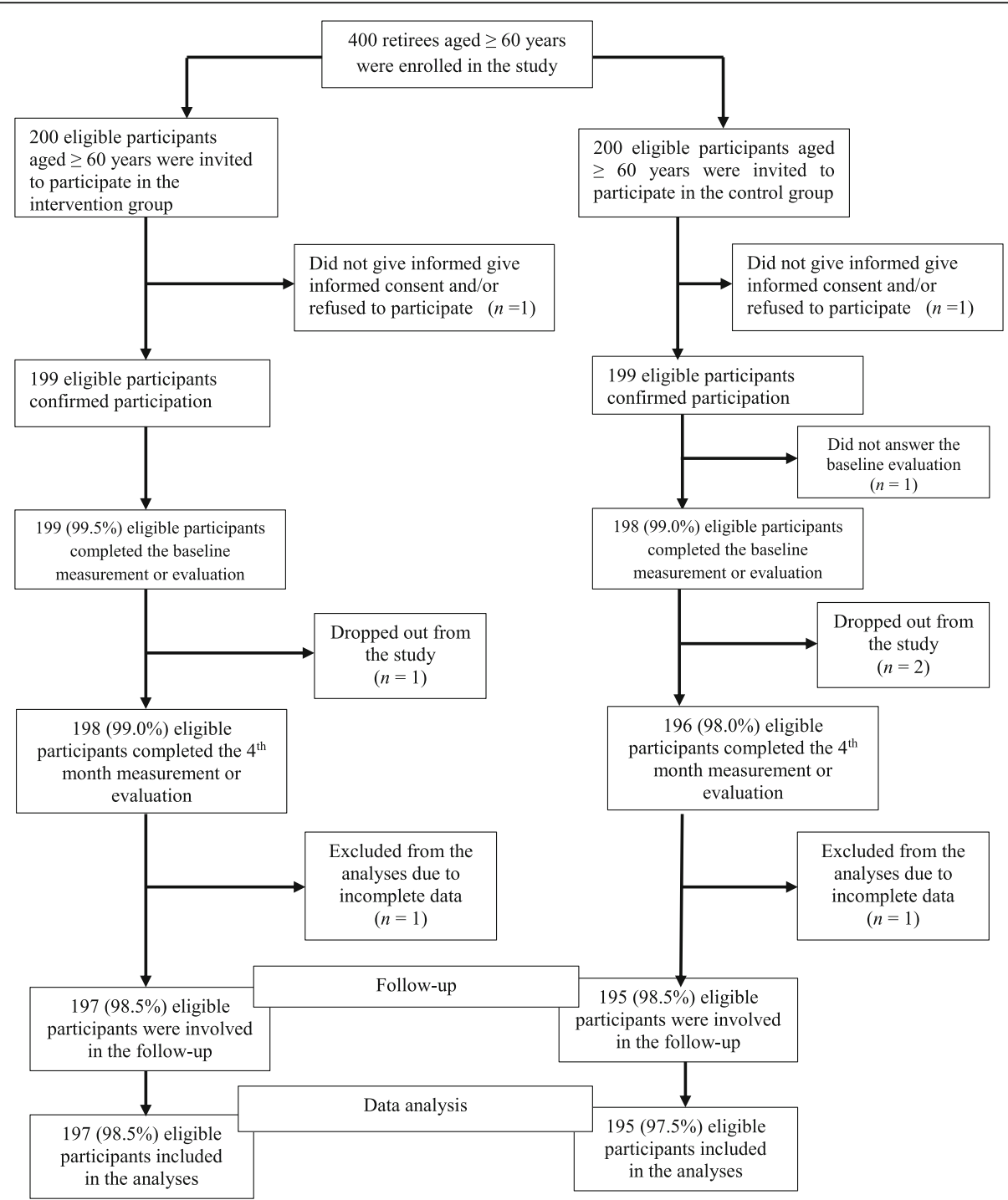

Fig. 1 Flow diagram of participants and analysis. Depicts the flow diagram of participants and analysis. There were 200 participants each in the treatment and control groups (T-Group, $n=200$; C-group, $n=200$ ). Of these populations, 98.5\% of participants in the intervention group and $97.5 \%$ of participants in the control group completed the study. The major reasons for refusing participation included lack of time/personal commitments, and illness. Incomplete data were also excluded from the analyses 
we conducted the face validity of the original 25 -item version of the HT knowledge questionnaire/sub-scale of by five public health education experts with the aim of determining what to measure and what not to measure; second, a coefficient of those was completed; and third, a coefficient of $\sim 0.5$ was valid at 0.75 , by the Items-Objective Congruence Index [43]. Secondly, the content validity of HT knowledge scale was evaluated through both quantitative and qualitative procedures. For the qualitative content validity assessment, 10 public health experts were interviewed and requested to evaluate the wording, readability, and clarity of the items, the accuracy of the dimensions and item distribution, and the correctness of the scoring protocol. The questionnaire was revised based on their observations. For the quantitative content validity assessment, 10 health education experts were invited to determine whether each item in the questionnaire was "necessary", "suitable but not necessary", or "not necessary at all". The experts' remarks were employed to compute the Content Validity Ratio (CVR). Based on the recommendation by Lawshe [44], items with a CVR of less than 0.62 were removed [45]. Subsequently, we required the experts to assess the relativity, simplicity, and clarity of the items by using a five-point Likert-type scale of "Not clear (1 point)", "Fairly clear ( 2 points)", "Clear (3 points)", "Very clear (4 points)", and "Absolutely clear (5 points)". We calculated the Content Validity Index (CVI) for each item by dividing the number of experts who had scored that item 4 or 5 by the total number of the experts [46]. We considered the items with a CVI of greater than 0.78 as having good content validity [47]. After these procedures, five items were excluded from the questionnaire.

Furthermore, a pilot study was conducted to assess the construct validity of the 20-item HT knowledge questionnaire. We administered copies of the 20-item questionnaire to 100 retirees who were not included in the main study. The principal component analysis (PCA) was used to examine the construct validity of the 20-item HT knowledge questionnaire. Before performing the PCA, we assessed the suitability of the data for factor analysis. Inspection of the correlation matrix showed the presence of many coefficients of .30 and above. The Kaiser-Meyer Olkin value was .65 [48], and Bartlett's Test of Sphericity reached statistical significance $(p$ $<.0001$ ), supporting the factorability of the correlation matrix [49]. The PCA showed the presence of 6 components with eigenvalues exceeding 1.00, explaining $62.2 \%$ of the variance. An inspection of the scree plot showed a clear break after the second component. Using the Cattell's scree test [50], it was decided to retain a two-factor solution component for further investigation. The two-factor component solution explained a total 33.5\% of the variance, with component 1 contributing $23.7 \%$ and component 2 contributing 9.8\%. The Oblimin rotation was performed to aid the interpretation of the results. The rotated solution showed the presence of simple structure [51], with both components showing some strong loadings and all variables loading substantially on only one component. There was a weak positive correlation between the two factors $(r=.05)$. The items loading 0.40 and above were retained. Using the pattern matrix, a total of 15 items were retained [52] (Additional file 2: Table S1 and S2). The 15-item HT knowledge questionnaire had a good reliability (Kuder-Richardson-20 coefficient was 0.72 ) (Additional file 3). We validated the intervention using two pension zones (i.e. pilot study). The zones were not included in the main study. Five health education experts with Ph.D. and M.Ed. Degrees, and three nurses with a B.Sc. degree and adequate work experience (the nurses work in tertiary health institutions in Enugu) facilitated the baseline, post-intervention and follow-up data collection process. The baseline, post-intervention and follow-up data were collected under the supervisions of the principal investigators.

\section{Covariates}

We collected the data on covariates which included the height and weight measurements for the body mass index (BMI) and blood pressure (BP) levels in the successive steps. We obtained written informed consent from the participants who fulfilled the inclusion criteria and were willing to participate in the study. The height and weight of all subjects were measured with an electronic digital scale at morning times between $10 \mathrm{a} . \mathrm{m}$. to 11:30 a.m. under light clothes without shoes. The BP levels were measured from the right and left arms of the subjects in a sitting position by the nurses at the study site (the study site was agreed upon by the retirees). The $\mathrm{BP}$ was measured twice with $10 \mathrm{~min}$ interval. The systolic BP (SBP) and diastolic BP (DBP) were recorded at the first and fifth Korotkoff phases respectively using calibrated mercury sphygmomanometers. We used the average of the four BP measurements for analysis. Using the Joint National Committee Report-7 (JNC 7) classification of blood pressure for adults [53], we classified the subjects' BP levels as follows: normal: $\mathrm{SBP}<120 \mathrm{mmHg}$ and DBP < $80 \mathrm{mmHg}$; PreHT: SBP $120-139 \mathrm{mmHg}$ and/ or DBP $80-89 \mathrm{mmHg}$; hypertension: $\mathrm{SBP} \geq 140 \mathrm{mmHg}$ and/or $\mathrm{DBP} \geq 90 \mathrm{mmHg}$. The subjects who have $\mathrm{BP}$ measurement of SBP $<140 \mathrm{mmHg}(\geq 60$ age, $\mathrm{SBP}<150$ $\mathrm{mmHg}$ ) and/or $\mathrm{DBP}<90 \mathrm{mmHg}$ at the time of study were classified as subjects with BP under control [40]. We considered the participants receiving antihypertensive treatment to have hypertension. The BMI was calculated by the formula $(\mathrm{BMI}=$ weight in $\mathrm{kg} /$ (height in $\mathrm{m}^{2}$ ) defined according to the WHO criteria [41]. Thus, 
we classified the participants as underweight $(\mathrm{BMI}=<$ $\left.18.5 \mathrm{~kg} / \mathrm{m}^{2}\right)$, normal weight $\left(\mathrm{BMI}=18.5-24.9 \mathrm{~kg} / \mathrm{m}^{2}\right)$, overweight $\left(\mathrm{BMI}=25.0-29.9 \mathrm{~kg} / \mathrm{m}^{2}\right)$, obese class I $(\mathrm{BMI}$ $\left.=30.0-34.9 \mathrm{~kg} / \mathrm{m}^{2}\right)$, obese class II $(B M I=35.0-39.9 \mathrm{~kg} /$ $\mathrm{m}^{2}$ ) or obese class III ( $\geq$ BMI $40 \mathrm{~kg} / \mathrm{m}^{2}$ ). However, for ease of analysis, we categorized all the participants with $\mathrm{BMI} \geq 30$ as obese.

\section{Measures}

\section{Demographic variables}

Demographic variables were assessed at the baseline. These included age (60-69 years, 70-79 years and $\geq 80$ years), gender, height, weight, systolic and diastolic BP, level of education (primary, secondary, tertiary education or its equivalent).

Hypertension knowledge The knowledge of HT was measured using a 15-item scale with a response format 'True,' 'False,' and 'I don't know.' The 15 questions were as follows: one question about the meaning of HT; four questions about causes and risk factors for HT, one question about signs and symptoms; two questions about BP measurement and its interpretation, four questions about HT complications and three questions about HT treatment and BP control [37-39]. The knowledge index ranged from 0 to 15 , with higher scores indicating greater HT knowledge post-intervention. We considered the mean HT knowledge scores at both the pre-intervention and post-intervention phases.

HT prevention and self-care practices The HT prevention and self-care practices sub-scale consists of 15 questions that focused on six domains such as regular physical activities (PA), adequate and quality sleep, abstinence/reduction in use of addictive substances, healthy diet, medication adherence and home BP monitoring (HBPM).

Physical activity We asked three questions about the participants' PA using the Short International Physical Activity Questionnaire Form "last seven days recall" (IPAQ-SF) [54]. The IPAQ-SF asks respondents to indicate frequency and duration of walking, moderate intensity, vigorous-intensity and sitting activity performed for at least $10 \mathrm{~min}$ duration per session in the last seven consecutive day period $[54,55]$. The PA categories may be examined independently to get the specific activity patterns or multiplied by their estimated value in Metabolic Equivalent of Tasks (METs) and summed to get an overall estimate of PA in a week [54-56]. This IPAQ-SF has been validated in Nigerian study [57]. We asked the participants about their PA levels in the past 7 days during the pre- and post-intervention phases. For instance, during the last 7 days, on how many days did you do vigorous physical activities like heavy lifting, digging, aerobics, or fast bicycling? During the last 7 days, on how many days did you do moderate physical activities like carrying light loads, bicycling at a regular pace, or doubles tennis? [54]. We excluded the item that elicits information on the total time spent sitting on a weekday. Participants were asked to indicate how much time (none, minutes and hours) they spent in doing such activities in the past 7 days. The PA measures used in this study included: minutes reported in vigorous, moderate, and walking activities and per week (Min week-1) and MET-minutes per week. We obtained the time spent in each activity category by multiplying the number of days per week with the minutes spent doing the activity per day and calculated the total weekly physical activity (MET-Min week-1) by multiplying the number of minutes spent in each activity category with the specific MET score for each activity. We made sure that the daily time spent on each of vigorous, moderate and walking activities ranged between 10 and $180 \mathrm{~min}$ for all participants. We used the MET intensity values to score IPAQ questions in this study. These included vigorous (8 METs), moderate (4 METs) and walking (3.3 METs) [54]. These categories followed the standard scoring criteria http://www.ipaq.ki.se. In this study, we assessed the PA using four scoring criteria as follows: none (0 points), walking METs of 3.3 (1 point), moderate activity with METs of 4 (2 points) and vigorous activity with 8 METs (3 points). The PA total score for the three items ranges from 0 to 9 points.

Quality and patterns of sleep We assessed the quality and patterns of sleep using three items from the Pittsburgh Sleep Quality Index (PSQI) [58]. The PSQI is a self-reported questionnaire that measures sleep quality and patterns during the previous month and evaluates seven components of sleep: subjective quality, latency, duration, usual efficiency, sleep disturbances, medication use, and daytime dysfunction. A score $>5$ is suggestive of a sleep disorder [58]. In this study, we used items $\# 6$ to \#8 of the PSQI. For instance, the questions included: During the past month, how often have you taken medicine to help you sleep (prescribed or "over the counter")? During the past month, how often have you had trouble staying awake while driving, eating meals, or engaging in social activity and during the past month, how much of a problem has it been for you to keep up enough enthusiasm to get things done? The items were assigned a Likert-type response format. Items \#6 and \#7 were assigned 'Not during the past one month ( 0 point)', 'less than once a week (1 point),' 'once or twice a week (2 points)', and 'three or more times a week (3 points)'. However, item 8 was assigned 'No problem at all', 'only a slight very problem,' 'somewhat of a problem, and 'a very 
big problem' [58]. The total score for the three items ranges from 0 to 9 points. However, we used an aggregate score of 3. A higher score on this scale is indicative of a sleep disorder, a lower score implies reduced sleep disorder, and a score of 0 suggests the absence of a sleep disorder.

Substance use abstinence/reduction Substance use abstinence/reduction was assessed using three items. The first items included: have you ever smoked a cigarette before? This item was assigned a response option of 'Yes, 'No', or 'never smoked'. The 'Yes' response was coded as 1 while the 'No' and 'never smoked' responses were coded 0 . Thus, a 'Yes' response to the question attracted 1 point while a 'No' or 'never smoked' response attracted 0 point. Alcohol use was measured using two items. For instance, "how often do you have a drink containing alcohol in a day, and how many alcoholic drinks do you consume on average per week?' The participants were asked to self-report how much alcohol they consumed on each drinking episode in the last 7 days. Since there is no Government recommended safe drinking guide in Nigeria, in that there are no alcohol policies [59], we asked the participants to describe their drinking in terms of the frequency of alcoholic drinks of various brands (beer, local gin, brandy, whiskey and other local alcoholic beverages) they had in the past 7 days. The first question was assigned a 3-point Likert-type scale of never $(0$ point),' '2-3 times a week (1 point),' $3-4$ times a week ( 2 points)' and ' $\geq 6$ times a week ( 3 points)'. The second question was also assigned a Likert-type response format of 'none (0 point), ' $1-2$ drinks ( 1 point)', $3-5$ drinks (2 points)', and ' $\geq 6$ drinks per week ( 3 points)'. Thus, the total score for this sub-scale ranges from 0 to 7 points. At the baseline, higher scores indicate harmful alcohol use. A score of 5-7 implies harmful alcohol use, a score of 1-4 implies moderate alcohol use and a score of $0 \mathrm{im}$ plies no substance use. Consequently, after the intervention, a score of 0 indicates no substance use or abstinence and a lower score indicates substance use reduction.

Healthy diet We used one item that measures healthy diet from the dietary screening questionnaire (SDQ) for older adults developed by Bailey et al. [60]. The SDQ is a 24-h recalls for temporal distribution of dietary intake with 2 Dietary patterns. Dietary pattern 1 is consistent with a "prudent" dietary pattern, whereas dietary pattern 2 could be considered "Western" or low nutrient dense. Dietary pattern 1 was characterized by fruits, vegetables, lean white meat, dairy, and whole grain products (mainly cereals). Dietary pattern 2 contained foods that would be considered lower in nutrient density, such as sweets and candy, processed meats, and salty snacks [60]. However, we formulated the question based on the Dietary pattern 1. For instance, on the average, in that past 7 days, how often do you consume the following food groups (fresh fruits, vegetables, chicken, fresh fish, dairy, and whole grain products such as rice, corn, sorghum, millet, beans, whole-wheat bread, etc.)? The item was assigned a Likert-type format of 'never (0 point), '1-2 times a week ( 1 point),' '3-5 times a week ( 2 points)', and 'more than 6 times a week ( 3 points)'. The total score for this item ranges from 0 to 3 points. Higher scores indicate healthier diet.

Medication adherence We used the 4-item Morisky Medication Adherence Scale (MMAS-4) or Morisky Scale [61-63] to assess medication adherence as a self-care practice in the two groups. The World Health Organization [64] defines adherence as the extent to which a person's behaviour - taking medication, following a diet and/or executing lifestyle changes, corresponds with agreed recommendations from a health care provider. The MMAS-4 is the quickest to administer and score and is able to ascertain barriers to adherence due to its length [61]. For instance, do you ever forget to take your anti-hypertensive/blood pressure medicine or other medicines prescribed by the doctor? The structured question format with "yes" bias indicates non-adherence. The MMAS-4 has been validated in the broadest range of diseases and in patients with low literacy [62]. The MMAS consists of four items with a scoring protocol of "Yes" (0) and "No" (1). Total MMAS-4 scores range from 0 to 4 and have been categorized into three levels of adherence: high adherence $($ score $=0)$, medium adherence (score of 1 to 2 ), and low adherence (score 3 to 4) [58].

Home blood pressure monitoring (HBPM) One of the most commonly recommended self-care practices for $\mathrm{HT}$ is the home blood pressure monitoring (HBPM). Evidence suggests that HBPM is "easy to perform, reliable, reproducible", [65, 66], cost-effective [64] and reduces office visits, and the number of medications [6668]. We assessed home blood pressure monitoring (HBPM) in this study using one item according to the National Institute for Clinical Excellence (NICE) guidelines [69]: using the following guidelines, how often do you monitor or take measurement of BP at home? The NICE guidelines for HBPM stipulate that when the HBPM is used to confirm a diagnosis of HT, it is essential to ensure that: 1) for each BP recording, two consecutive measurements are taken, at least $1 \mathrm{~min}$ apart with the person seated; 2) BP is recorded twice daily, ideally in the morning and evening; and 3) BP recording continues for at least 4 days, ideally for 7 days. The NICE guidelines for HBPM were outlined to guide the 
participants' responses to the item. The guidelines were assigned a response format of "Never (0 point)", rarely (1 point),' 'occasionally ( 2 points)', and 'always ( 3 points)'. Thus, the score index ranges from 0 to 9 points. However, we used an aggregate score of 3 points. Higher scores imply effective HBPM. Furthermore, the Cronbach's alpha coefficient for the HT prevention and self-care practices scale was 0.84 (Additional file 4).

\section{Data processing and statistical analysis}

We used the exploratory factor analysis (EFA) via the principal component analysis (PCA) and Oblimin rotation to validate the factor structure of the questionnaire as earlier explained. The EFA was conducted using the original 40-item questionnaire to determine whether the measures of construct were consistent with the authors' comprehension of the nature of that construct. Ten items were excluded during data analysis due to low correlations. Thus, 30 items of the questionnaire were used for the study and included in the analysis. The comparisons of the demographic characteristics between the intervention/treatment and control groups at baseline were examined using independent samples $t$-test for continuous variables and Chi-square test for categorical variables. To examine the intervention effects on HT knowledge, prevention and self-care practices, one-way repeated measures analysis of variance (ANOVA) with time (baseline, 4th month and follow-up) as within-subjects factor and group (intervention/control) as between-subjects factor were performed. We conducted preliminary analyses to ensure that there was no infraction of the assumption of normality, linearity, homogeneity of variance and reliable measurement of the covariates. Missing measurements as a result of a participant's withdrawal from the study were excluded from data analyses. Statistical significance was set at $p<$ 0.05. The analyses were performed using the IBM SPSS 20.0 (IBM Corp., Armonk, NY, USA).

\section{Results}

\section{Characteristics of the participants}

We enrolled 400 participants in the study. The mean age of the participants was $65.9( \pm 8.9)$ years, mean SBP and DBP were $136.5( \pm 13.3)$ and $87.9( \pm 9.1)$ respectively. The mean BMI was $23.9( \pm 5.1) \mathrm{kg} / \mathrm{m}^{2}$. In total, majority of the participants was in age group 60-69 years (68.4), 50.3 and $49.7 \%$ of the sample were male and female respectively, and $55.9 \%$ had a tertiary education. The result further showed that more than half of the participants were hypertensive (55.6\%) and majority had normal BMI (61.5\%). The Chi-square tests showed that there were significant baseline differences between the groups based on gender and BMI categories. The independent samples $\mathrm{t}$-tests showed that no significant differences were found in the mean SBP, DBP and BMI between the intervention group and control group (Table 1).

\section{Before and after the intervention differences in HT knowledge}

Results of the paired comparison indicated that the mean HT knowledge of all the participants increased between the baseline (pre-test) and after the intervention (post-test). After the health education intervention, the mean HT knowledge score significantly increased in the T-group between baseline and 1 month (4th month) compared to those in the C-group $(p<0.0001)$ (Table 2).

\section{Before and after the intervention differences in HT prevention and self-care practices}

Regarding the HT prevention and self-care practices (PSC), after the intervention, significant differences existed between the two groups. The paired samples analyses showed that PA increased significantly in the T-group, whereas no increase was found the in $\mathrm{C}$-group between baseline and after intervention $(P=0.007)$. Additionally, sleep pattern and quality $(P=0.003)$, substance use abstinence $(P=0.000)$, healthy diet $(P=0.000)$, and medication adherence $(P=0.000)$ improved significantly in the T-group between baseline and 1 month after intervention, whereas the control remained similar, decreased or slightly increased between baseline and 1 month after intervention (Table 3). However, no significant difference was found for HBPM between the two groups 1 month after the intervention $((P=0.21)$ (Table 3).

\section{Intervention effects on HT knowledge, prevention and self-care practices}

The one-way repeated measures ANOVA analyses showed statistically significant effects (between-groups analysis $)$ for HT knowledge $(P=0.000, \eta p 2=0.36)$, physical activity $(P=0.000, \eta \mathrm{p} 2=0.06)$, sleep pattern and quality $(P=0.000 ; \eta \mathrm{p} 2=0.08)$, substance use abstinence $(P=0.000 ; \eta \mathrm{p} 2=0.21)$, healthy $\operatorname{diet}(P=0.000 ; \eta \mathrm{p} 2=$ $0.30)$, medication adherence $(P=0.000 ; \eta \mathrm{p} 2=0.28)$, and HBPM $(P=0.000 ; \eta p 2=0.10)$ with small to large effect sizes [70] (Table 4) (Additional files 5, 6, 7, 8, 9 and 10). The effect sizes ranged from 0.06 to 0.36 , showing that the intervention effects are both limited and substantial practical significance. The paired samples analyses indicated that HT knowledge significantly increased between baseline and 2-month follow-up in T-group compared to the control group $(P=0.000)$. A similar result was obtained for PA between baseline and 2-month follow-up $(P=0.000)$. Additionally, PSC such as physical activity $(P=0.000)$, sleep pattern and quality $(P=0.000)$, substance use abstinence $(P=0.000)$, healthy $\operatorname{diet}(P=$ $0.000)$, medication adherence $(P=0.000)$, and HBPM 
Table 1 Demographic characteristics of the sample at baseline

\begin{tabular}{|c|c|c|c|c|c|}
\hline Characteristics & $\begin{array}{l}\text { Total sample } \\
(N=392)\end{array}$ & $\begin{array}{l}\text { Intervention group } \\
(n=197)\end{array}$ & $\begin{array}{l}\text { Control group } \\
(n=195)\end{array}$ & $x^{2} / t$ & $P$-value \\
\hline Age, mean (SD) & $65.9(8.9)$ & $65.6(8.4)$ & $66.2(9.3)$ & & \\
\hline Age, $n(\%)$ & & & & 1.88 & 0.39 \\
\hline 60-69 years & $268(68.4)$ & $141(71.6)$ & $127(65.1)$ & & \\
\hline 70-79years & $95(24.2)$ & $43(21.8)$ & $52(26.7)$ & & \\
\hline$\geq 80$ years & $29(7.4)$ & $13(6.6)$ & $16(8.2)$ & & \\
\hline Gender, $n(\%)$ & & & & 13.23 & $.000^{*}$ \\
\hline Male & $197(50.3)$ & $81(41.1)$ & $116(59.5)$ & & \\
\hline Female & $195(49.7)$ & $116(58.9)$ & $79(40.5)$ & & \\
\hline Educational level, $n$ (\%) & & & & 0.18 & 0.91 \\
\hline Primary education & $56(14.3)$ & $29(14.7)$ & $27(13.8)$ & & \\
\hline Secondary education & $117(29.8)$ & $60(30.5)$ & $57(29.2)$ & & \\
\hline Tertiary education & 219 (55.9) & $108(54.8)$ & $111(50.7)$ & & \\
\hline \multicolumn{6}{|l|}{ Current BP } \\
\hline SBP, mean (SD) & $136.5(13.3)$ & $137.2(12.9)$ & $135.9(13.5)$ & -0.88 & 0.38 \\
\hline $\mathrm{DBP}$, mean (SD) & $87.9(9.1)$ & $88.2(9.9)$ & $87.7(8.1)$ & -0.45 & 0.65 \\
\hline BP Categories n (\%) & & & & 3.61 & 0.17 \\
\hline Normal & $41(10.5)$ & $15(7.6)$ & $26(13.3)$ & & \\
\hline Pre-HT & $133(33.9)$ & $67(34.0)$ & $66(33.8)$ & & \\
\hline $\mathrm{HT}$ & $218(55.6)$ & $115(58.4)$ & $103(52.8)$ & & \\
\hline BMI, mean (SD) & $23.9(5.1)$ & $23.8(5.4)$ & $23.9(4.8)$ & 0.04 & 0.97 \\
\hline BMI Categories, n (\%) & & & & 8.64 & $0.04^{* *}$ \\
\hline Underweight & $38(9.7)$ & $27(13.7)$ & $11(5.6)$ & & \\
\hline Normal & $241(61.5)$ & $117(59.4)$ & $124(63.6)$ & & \\
\hline Overweight & $66(16.8)$ & $28(14.2)$ & $38(19.5)$ & & \\
\hline Obese & $47(12.0)$ & 25 (12.7) & $22(11.3)$ & & \\
\hline
\end{tabular}

HT Hypertension, BMI Body Mass Index, BP blood pressure, SBP Systolic blood pressure, DBP Diastolic blood pressure. ${ }^{*} P<.001$; ${ }^{*} P<0.05$

$(P=0.000)$ significantly improved between baseline and 2-month follow-up in the T-group than C-group (Table 4). The one-way repeated measures ANOVA analyses showed significant time-by-group interaction effects (within-groups) for HT knowledge $(P=0.000, \eta \mathrm{p} 2=$ $0.34)$, physical activity $(P=0.000, \eta \mathrm{p} 2=0.04)$, sleep pattern and quality $(P=0.000 ; \eta \mathrm{p} 2=0.06)$, substance use abstinence $(P=0.000 ; \eta \mathrm{p} 2=0.16)$, healthy $\operatorname{diet}(P=$ $0.000 ; \eta \mathrm{p} 2=0.28)$, medication adherence $(P=0.000 ; \eta \mathrm{p} 2$

Table 2 HT knowledge in the groups at baseline and after intervention

\begin{tabular}{lll}
\hline & $\begin{array}{l}\text { Intervention group } \\
(n=197)\end{array}$ & $\begin{array}{l}\text { Control group } \\
(n=195)\end{array}$ \\
\hline Time & Mean \pm SD & Mean \pm SD \\
\hline Baseline & $9.64 \pm 3.35$ & $9.69 \pm 3.52$ \\
After intervention & $12.63 \pm 2.13$ & $9.71 \pm 3.47$ \\
Paired samples T-test results & $P=0.000^{*}$ & $P=0.57$ \\
\hline
\end{tabular}

${ }^{*} P<0.0001$
$=0.26)$, and $\operatorname{HBPM}(P=0.000 ; \eta p 2=0.04)$ with small to large effect sizes [70] (Table 5) (Additional files 5, 6, 7, 8, 9 and 10).

\section{Discussion}

The results of our study showed that the educational intervention had a positive effect on increasing retirees' HT knowledge, and any other individual outcome. Our findings have contributed to limited data on the effectiveness of health education interventions in sub-Saharan Africa. In the T-group, the mean HT knowledge significantly increased between baseline and 1 month (4th month) compared to the C-group. Adequate knowledge of HT and its prevention has been identified as a precondition for lifestyle modifications, medication adherence and effective control of BP among hypertensive patients and older adults [22,23]. This finding is consistent with a previous study that reported higher post-test scores on hypertension knowledge, attitude and practices (KAP) than the pre-test scores [71]. Several studies have 
Table 3 Dimensions of HT prevention and self-care practices in treatment and control groups at baseline and after the intervention

\begin{tabular}{|c|c|c|c|c|}
\hline Time & Dimensions of HT prevention \& self-care practices & $\begin{array}{l}\text { Intervention group } \\
\text { Mean } \pm \text { SD }\end{array}$ & $\begin{array}{l}\text { Control group } \\
\text { Mean } \pm \text { SD }\end{array}$ & $\begin{array}{l}{ }^{*} \text { Test results } \\
P \text {-value }\end{array}$ \\
\hline \multicolumn{5}{|c|}{ Baseline } \\
\hline & Physical activity & $1.92 \pm 0.97$ & $1.90 \pm 1.01$ & 0.76 \\
\hline & Sleep pattern \& quality & $1.87 \pm 1.10$ & $1.95 \pm 0.93$ & 0.10 \\
\hline & Substance use abstinence & $2.29 \pm 0.92$ & $2.15 \pm 0.83$ & 0.51 \\
\hline & Healthy diet & $0.76 \pm 0.43$ & $0.72 \pm 0.45$ & 0.08 \\
\hline & Medication adherence & $2.27 \pm 1.18$ & $2.26 \pm 1.66$ & 0.07 \\
\hline & HBPM & $1.42 \pm 0.83$ & $1.57 \pm 0.74$ & 0.49 \\
\hline \multicolumn{5}{|c|}{ After intervention } \\
\hline & Physical activity & $2.15 \pm 0.81$ & $1.90 \pm 1.02$ & $0.007^{* *}$ \\
\hline & Sleep pattern \& quality & $1.57 \pm 1.04$ & $1.95 \pm 0.95$ & $0.003^{* *}$ \\
\hline & Substance use abstinence & $1.68 \pm 1.02$ & $2.10 \pm 0.94$ & $0.000^{*}$ \\
\hline & Healthy diet & $1.27 \pm 0.65$ & $0.74 \pm 0.44$ & $0.000^{*}$ \\
\hline & Medication adherence & $1.86 \pm 1.06$ & $2.44 \pm 0.83$ & $0.000^{*}$ \\
\hline & HBPM & $1.51 \pm 0.69$ & $1.57 \pm 0.65$ & 0.21 \\
\hline
\end{tabular}

*Paired samples t-test. HBPM, Home blood pressure monitoring

${ }^{*} P<0.0001 ;{ }^{* *} P<0.001$

Table 4 Intervention effects on HT knowledge, prevention and self-care practices

\begin{tabular}{|c|c|c|c|c|c|c|}
\hline Measures & $\begin{array}{l}\text { Baseline } \\
\text { Mean } \pm \text { SD }\end{array}$ & $\begin{array}{l}\text { After } \\
\text { intervention } \\
\text { (4th month) } \\
\text { Mean } \pm S D\end{array}$ & $\begin{array}{l}\text { Follow-up } \\
\text { (5th month) } \\
\text { Mean (SD) }\end{array}$ & $F$ & пр2 & $\begin{array}{l}\text { Paired analyses } \\
\text { Baseline \& follow-up P-value }\end{array}$ \\
\hline \multicolumn{7}{|l|}{ HT knowledge } \\
\hline Intervention group & $9.64 \pm 3.35$ & $12.63 \pm 2.13$ & $13.13 \pm 1.39$ & $108.12^{*}$ & 0.36 & $0.000^{*}$ \\
\hline Control group & $9.69 \pm 3.52$ & $9.71 \pm 3.47$ & $9.76 \pm 3.42$ & & & 0.16 \\
\hline \multicolumn{7}{|l|}{ HT PSC } \\
\hline \multicolumn{7}{|l|}{ Physical activity } \\
\hline Intervention group & $1.92 \pm 0.97$ & $2.15 \pm 0.81$ & $2.06 \pm 0.88$ & $12.71^{*}$ & 0.06 & $0.000^{*}$ \\
\hline Control group & $1.90 \pm 1.01$ & $1.90 \pm 1.02$ & $1.91 \pm 0.99$ & & & 0.59 \\
\hline \multicolumn{7}{|l|}{ Sleep pattern and quality } \\
\hline Intervention group & $1.87 \pm 1.10$ & $1.57 \pm 1.04$ & $1.41 \pm 0.99$ & $17.75^{*}$ & 0.08 & $0.000^{*}$ \\
\hline Control group & $1.95 \pm 0.93$ & $1.95 \pm 0.95$ & $1.92 \pm 0.93$ & & & 0.05 \\
\hline \multicolumn{7}{|c|}{ Substance use abstinence } \\
\hline Intervention group & $2.29 \pm 0.92$ & $1.68 \pm 1.02$ & $1.20 \pm 0.98$ & $52.67^{*}$ & 0.21 & $0.000^{*}$ \\
\hline Control group & $2.15 \pm 0.83$ & $2.10 \pm 0.94$ & $2.06 \pm 0.95$ & & & 0.28 \\
\hline \multicolumn{7}{|l|}{ Healthy diet } \\
\hline Intervention group & $0.76 \pm 0.43$ & $1.27 \pm 0.65$ & $1.63 \pm 0.82$ & $81.98^{*}$ & 0.30 & \\
\hline Control group & $0.72 \pm 0.45$ & $0.74 \pm 0.44$ & $0.74 \pm 0.45$ & & & 0.10 \\
\hline \multicolumn{7}{|l|}{ Medication adherence } \\
\hline Intervention group & $2.27 \pm 1.18$ & $1.86 \pm 1.06$ & $0.91 \pm 0.94$ & $75.19^{*}$ & 0.28 & $0.000^{*}$ \\
\hline Control group & $2.26 \pm 1.66$ & $2.44 \pm 0.83$ & $2.27 \pm 1.14$ & & & 0.08 \\
\hline \multicolumn{7}{|l|}{ HBPM } \\
\hline Intervention group & $1.42 \pm 0.83$ & $1.51 \pm 0.69$ & $1.78 \pm 0.77$ & $20.88^{*}$ & 0.10 & $0.000^{*}$ \\
\hline Control group & $1.57 \pm 0.74$ & $1.57 \pm 0.65$ & & & & 0.15 \\
\hline
\end{tabular}

HT hypertension, PSC Prevention and self-care, HBPM home blood pressure monitoring

$F$ Wilks' lambda $F$ value, $\eta p 2$ partial eta squared

${ }^{*} P<0.0001$ 
Table 5 Intervention effects (time by group interaction) on HT knowledge, prevention and self-care practices

\begin{tabular}{|c|c|c|c|c|c|}
\hline Measures & $\begin{array}{l}\text { Baseline } \\
\text { Mean } \pm \text { SD }\end{array}$ & $\begin{array}{l}\text { After intervention (4th month) } \\
\text { Mean } \pm \text { SD }\end{array}$ & $\begin{array}{l}\text { Follow-up } \\
\text { (5th month) } \\
\text { Mean (SD) }\end{array}$ & F Time by group & np2 \\
\hline \multicolumn{6}{|l|}{ HT knowledge } \\
\hline Intervention group & $9.64 \pm 3.35$ & $12.63 \pm 2.13$ & $13.13 \pm 1.39$ & \multirow[t]{2}{*}{$98.54^{*}$} & \multirow[t]{2}{*}{0.34} \\
\hline Control group & $9.69 \pm 3.52$ & $9.71 \pm 3.47$ & $9.76 \pm 3.42$ & & \\
\hline \multicolumn{6}{|l|}{ HT PSC } \\
\hline \multicolumn{6}{|l|}{ Physical activity } \\
\hline Intervention group & $1.92 \pm 0.97$ & $2.15 \pm 0.81$ & $2.06 \pm 0.88$ & \multirow[t]{2}{*}{$8.09^{*}$} & \multirow[t]{2}{*}{0.02} \\
\hline Control group & $1.90 \pm 1.01$ & $1.90 \pm 1.02$ & $1.91 \pm 0.99$ & & \\
\hline \multicolumn{6}{|c|}{ Sleep pattern and quality } \\
\hline Intervention group & $1.87 \pm 1.10$ & $1.57 \pm 1.04$ & $1.41 \pm 0.99$ & \multirow[t]{2}{*}{$12.76^{*}$} & \multirow[t]{2}{*}{0.06} \\
\hline Control group & $1.95 \pm 0.93$ & $1.95 \pm 0.95$ & $1.92 \pm 0.93$ & & \\
\hline \multicolumn{6}{|c|}{ Substance use abstinence } \\
\hline Intervention group & $2.29 \pm 0.92$ & $1.68 \pm 1.02$ & $1.20 \pm 0.98$ & \multirow[t]{2}{*}{$37.94^{*}$} & \multirow[t]{2}{*}{0.16} \\
\hline Control group & $2.15 \pm 0.83$ & $2.10 \pm 0.94$ & $2.06 \pm 0.95$ & & \\
\hline \multicolumn{6}{|l|}{ Healthy diet } \\
\hline Intervention group & $0.76 \pm 0.43$ & $1.27 \pm 0.65$ & $1.63 \pm 0.82$ & \multirow[t]{2}{*}{$74.66^{*}$} & \multirow[t]{2}{*}{0.28} \\
\hline Control group & $0.72 \pm 0.45$ & $0.74 \pm 0.44$ & $0.74 \pm 0.45$ & & \\
\hline \multicolumn{6}{|l|}{ Medication adherence } \\
\hline Intervention group & $2.27 \pm 1.18$ & $1.86 \pm 1.06$ & $0.91 \pm 0.94$ & \multirow[t]{2}{*}{$69.16^{*}$} & \multirow[t]{2}{*}{0.26} \\
\hline Control group & $2.26 \pm 1.66$ & $2.44 \pm 0.83$ & $2.27 \pm 1.14$ & & \\
\hline \multicolumn{6}{|c|}{ Home blood pressure monitoring } \\
\hline Intervention group & $1.42 \pm 0.83$ & $1.51 \pm 0.69$ & $1.78 \pm 0.77$ & $8.24^{*}$ & 0.04 \\
\hline Control group & $1.57 \pm 0.74$ & $1.57 \pm 0.65$ & & & \\
\hline
\end{tabular}

$H T$ hypertension, PSC Prevention and self-care, $F$ Wilks' lambda $F$ value, $\eta p 2$ partial eta squared

${ }^{*} P<0.0001$

indicated the prevalence of poor knowledge about HT among older adults $[19,20,24]$. Therefore, valid and culturally contextualized health education intervention on HT is vital for increasing knowledge among the hypertensive and non-hypertensive older adults. Implementation of health education interventions that target knowledge improvement among older adults in diverse regions in Nigeria may reduce the prevalence of HT and its associated disability, mortality and morbidities in this sub-population. However, evidence suggests knowledge does not always lead to the desired behavioural change [72].

According to the study findings, HT prevention and self-care practices such as PA, sleep pattern and quality, substance use abstinence, healthy diet, and medication adherence increased or improved significantly in the T-group compared with the control group between baseline and 1 month after intervention. The present study shows that a culturally sensitive and well-organized model-based educational intervention has the potential to improve prevention and self-care practices of older adults. Thus, the study validates the beneficial effects of health education interventions on lifestyle modification among older adults. The findings are compatible with previous studies that reported improvement in self-care practices of HT in older patients [71, 73]. However, no significant difference was found for HBPM between the two groups at 1 month after the intervention. Some plausible reasons may explain this finding. Firstly, unavailability of a BP monitoring device due to its cost and lack of the required skills for effective use may be implicated. Evidence suggests that the use of auscultatory devices (mercury, aneroid or other) is not recommended for HBPM because their use requires the presence of a trained observer while BP monitors that use the oscillometric method are recommended [65, 68]. However, the cost of BP monitoring devices in Nigeria seems too exorbitant for the poor. For instance, the M2 basic automatic blood pressure and the OMRON M7 intelli IT are sold for about \#14,000 (\$38.4, i.e. \#365/USD) and \#35,000 (\$95.9) respectively in the pharmaceutical stores or retails. Due to economic downturn, many retirees in 
Nigeria do not receive their monthly stipends regularly. Therefore, some retirees may not have the money to buy the BP monitors. Hence, it becomes imperative for policy makers, and government to fully subsidize health care products such as BP monitors for older adults. In addition, older adults including retirees should be given free BP monitors at health facilities. A lack of the necessary skills is another potential factor that may explain this finding. For instance, evidence suggests that effective HBPM requires the hearing acuity of the operator, the sensitivity of the stethoscope, positioning of the cuff bladder center is directly above the brachial artery, and validation of the automatic electronic $\mathrm{BP}$ monitors before use $[74,75]$. Although, we provided demonstrations on self-BP measurements during the intervention, it is possible that some retirees did not acquire enough skills in the short-term. The one-month post intervention period may probably be too short for participants to observe full uptake of HBMP. Thus, convincing effects of the intervention HBPM may not be expected in the short-term period. This finding contradicts a previous study [73]. Further research is needed to investigate whether retirees who received long-term educational intervention on HT have improved HBPM outcomes.

Furthermore, considering the underlying constructs of IMB model [36, 73], the intervention focused on increasing HT knowledge and improving prevention and self-care practices of HT. The conceptualization of the IMB model holds that information, motivation, and behavioral skills are the fundamental determinants of a preventive behavior [36, 73]. Although, the IMB was developed to predict HIV preventive behavior and necessary components of HIV prevention intervention, it has been applied to other areas [76, 77]. The post-intervention and follow-up (i.e., 5th month) effects of the intervention were significant. The follow-up intervention was meant to reinforce the key outcomes of the study in the T-group. After evaluation of the primary outcomes at 1-month post-intervention, we observed the need for a follow-up. After the follow-up, the participants' HT knowledge increased considerably and there were significant changes in the HT prevention and self-care practices. This reflected in the significant between- and within-group effects observed in the T-group compared with the C-group. This implies that the intervention effects are of considerable practical significance for public health. This finding is compatible with previous studies $[71,73]$. This finding suggests the need for the implementation of more cost-effective and culturally sensitive educational interventions among older adults in Nigeria. Educational interventions use behavioural change techniques (e.g., provision of personal feedback, goal-setting, and self-monitoring of behaviour etc.) that facilitate maintenance or sustenance of health behaviours [27]. Furthermore, compared to controlled clinical trials, educational interventions may be more accessible to hard-to-reach populations (e.g. people in isolated communities or creeks in the Niger Delta region) in Nigeria.

\section{Strength and limitations}

The strength of this study was the use of a quasi-experimental design to determine the effectiveness of a health education intervention delivered in a community setting. The quasi-experimental (non-randomized) studies are increasingly adopted to evaluate population health interventions by health experts $[78,79]$. Furthermore, the findings of such studies are probably useful to policymakers when the intervention is conducted under real-life situations without manipulation for research [80]. The findings of the study are also consistent with previous research [71-73]. Also, the intervention was theory based and integrated cogent constructs of IMB model. To our knowledge, this is the first study assessing the effects of an IMB model-based health education intervention on HT knowledge and other individual outcomes among older adults in south-east, Nigeria.

However, the study has several limitations. One major limitation is the potential effects of external factors or interventions unconnected to the current intervention. For instance, life events such as onset of illness, disability, and involvement in other intervention in a health facility might have influenced participants' responses either positively or negatively. Another limitation of the study is the relatively small sample size. Although, the priori power analysis showed that our sample was adequate for the study; however, a relatively small sample size makes our study more exposed to the potentially confounding effects of life events. For instance, it is likely that there was an improvement in a retiree's HT knowledge, prevention and self-care practices after the intervention and follow-up, this improvement may be invalidated by adverse life events such as death of a family member. The use of larger samples and more rigorous study design such as randomized controlled trials (RCTs) in future studies would mitigate the effects of potentially confounding variables.

The study timeframe is another limitation. The length of time for substantial change in the HT prevention and self-care practice was relatively short. The follow-up period (i.e., 2 months after the intervention) might not be enough. Therefore, the long-term effects of the intervention could not be assessed. For instance, there was a marginal improvement in the participants' PA 1 month after intervention, and a slight reduction in PA score 2 months after the intervention. Thus, longer follow-up 
(e.g. 6 months or 1 year) is necessary to assess maintenance of PSC practices in future studies.

In this study, there were significant baseline differences between the groups based on gender and BMI categories. Also, there are more women in the T-group compared to the C-group. The observed gender difference in the study might have influenced the study outcomes. Although, we tried to ensure gender balance in the allocation of participants to both the T-group and C-group, the dropouts were predominantly males. Evidence suggests [81] that significant gender differences exist in some aspects of therapy, coping behaviour, and help-seeking. Since women are known to be more concerned with their health than men, they could also be more responsive than men to a health education intervention designed to improve their HT knowledge, prevention and self-care practices. Thus, the success of future health interventions could improve greatly if gender of participants is considered and gender balance is ensured by researchers. Future studies may benefit from interventions designed with features to attract and retain male participants and reduce dropout rates. Furthermore, there were BMI differences in both groups at the baseline and the differences might have impacted the study results. Nevertheless, we believe that the random assignment of participants to both groups would have reduced the effect of participants' BMI on the study outcomes. Future studies employing RCTs might investigate the effect of participants' BMI on similar health interventions.

We used self-report measures in this study, which may introduce response bias. However, we believe that the use of well-validated scales would minimize the bias. Additionally, this study only included retirees in Enugu state, so the results may not be generalizable to other older adults who retired from the federal civil service or private firms, and those who are self-employed. This may have also limited its generalizability. Repetition of this study with other categories of older adults in diverse settings and communities in Nigeria would thus be needed. We also observed few dropouts in both groups. Dropout has been identified to limit the generalizability of findings [27]. It also suggests that some aspects of the intervention may be too arduous or time-consuming for the participants. Therefore, future research should tackle the exact reasons for dropout.

\section{Conclusion}

Overall, our findings provide evidence for the efficacy of a community-based health education intervention in retirees and validated the importance of adopting IMB model in this group. Hence, a community-based health education intervention/programme targeted at older adults can increase HT knowledge, improve prevention and self-care practices at the population level. Also, further research is needed to develop preventive health interventions based on the Information-MotivationBehavioral (IMB) Skills model to increase knowledge about HT, promote prevention and self-care behaviours among Nigerian retirees in diverse settings.

\section{Additional files}

Additional file 1: Results of the statistical power analysis using $\mathrm{G}$ power software. (DOCX $75 \mathrm{~kb}$ )

Additional file 2: Results of exploratory factor analysis. (XLS $81 \mathrm{~kb}$ ) Additional file 3: Cronbach alpha reliability test for hypertension knowledge scale. (XLS 34 kb)

Additional file 4: Cronabch alpha reliability test for HT prevention \& self-care practices scale. (XLS $34 \mathrm{~kb}$ )

Additional file 5: Results of one-way repeated measures ANOVA for HT knowledge T1-T3. (XLS 39 kb)

Additional file 6: Results of one-way repeated measures ANOVA for HBPM T1-T3. (XLS 39 kb)

Additional file 7: Results of one-way repeated measures ANOVA for healthy diet T1-T3. (XLS $39 \mathrm{~kb}$ )

Additional file 8: Results of one-way repeated measures ANOVA for medication adherence T1-T3. (XLS 39 kb)

Additional file 9: Results of one-way repeated measures ANOVA for PA T1-T3. (XLS 39 kb)

Additional file 10: Results of one-way repeated measures ANOVA for Sleep quality T1-T3. (XLS 39 kb)

Additional file 11: Results of one-way repeated measures ANOVA for substance use T1-T3. (XLS 39 kb)

Additional file 12: Results of paired samples T-tests. (DOCX $20 \mathrm{~kb}$ )

\section{Abbreviations}

ANOVA: Analysis of Variance; BMI: Body Mass Index; CVD: Cardiovascular Disease; DBP: Diastolic Blood Pressure; HBPM: Home Blood Pressure Monitoring; HT: Hypertension; IMB: Information-Motivation-Behavioral Skills Model; IPAQ-SF: Short International Physical Activity Questionnaire Form; LGAs: Local Government Areas; METs: Metabolic Equivalent of Tasks; MMAS4: 4-item Morisky Medication Adherence Scale; NUP: Nigeria Union of Pensioners; PA: Physical Activity; PCA: Principal Component Analysis; PSC: Prevention and Self-care; PSQI: Pittsburgh Sleep Quality Index; SBP: Systolic Blood Pressure; SDQ: Dietary Screening Questionnaire

\section{Acknowledgments}

We would like to express our sincere gratitude to the leaders of the selected pension zones, nurses, and health educators for their support during data collection for this study. We sincerely appreciate all the retirees involved in the study for their cooperation and provision of necessary information.

\section{Funding}

Not applicable.

\section{Availability of data and materials}

The dataset(s) supporting the conclusions of this article is (are) included within the article (and its additional files 1, 2, 3, 4, 5, 6, 7, 8, 9, 10, 11 and 12 .

\section{Authors' contributions}

$\mathrm{EO}, \mathrm{Cl}, \mathrm{OSA}, \mathrm{PCl}$ and OCE, made substantial contributions to conception and design; EO, OSA, AMA, PCO, and CUO assisted in data collection, OSA, EO and $\mathrm{Cl}$ analyzed the data; $\mathrm{EO}, \mathrm{OSA}, \mathrm{OCE}, \mathrm{EA}$, and $\mathrm{BNA}$ were involved in interpretation and drafting the manuscript. All authors have read and given final approval of the version to be published; and agreed to be responsible for all aspects of the work in ensuring that questions related to the accuracy 
and integrity of any section of the work are appropriately investigated and resolved.

\section{Ethics approval and consent to participate}

The study was approved by the Ethical Committee on Research Projects, Enugu State Ministry of Health (Ref Number: MH/MSD/EC/0192). The participants were fully informed about the study objectives, their role, the risks involved in the study, voluntary nature of their participation and that they could decline or pull out of the study any time they wished. Copies of the questionnaires were administered only after receiving written informed consent from all participants. Confidentiality of the disclosed information was also assured and maintained to minimize potential risks to respondents. Completed questionnaires were kept secured and coded with each participant's identification number. We also registered the trial retrospectively with the Pan African Clinical Trial Registry (www.pactr.org) database. The identification number for the registry is PACTR201901779740173.

\section{Consent for publication}

This is our original research work. We want to publish it at archives of public health.

\section{Competing interests}

The authors declare that they have no competing interests.

\section{Publisher's Note}

Springer Nature remains neutral with regard to jurisdictional claims in published maps and institutional affiliations.

\section{Author details}

${ }^{1}$ Department of Human Kinetics and Health Education, Faculty of Education, University of Nigeria, Nsukka, Enugu State, Nigeria. ${ }^{2}$ Department of Public Health, Faculty of Health Sciences, Madonna University Elele, Port Harcourt, Rivers State, Nigeria. ${ }^{3}$ Department of Human Kinetics, Health and Safety Education, Ignatius Ajuru University of Education, Port Harcourt, Rivers State, Nigeria.

Received: 25 January 2019 Accepted: 30 April 2019

Published online: 23 May 2019

\section{References}

1. GBD 2015 Risk Factors Collaborators. Global, regional, and national comparative risk assessment of 79 behavioural, environmental and occupational, and metabolic risks or clusters of risks, 1990-2015: a systematic analysis for the Global Burden of Disease Study 2015. Lancet. 2016;388:1659-1724. 3

2. Mills KT, Bundy JD, Kelly TN, Reed JE, Kearney PM, Reynolds K, Chen J, He J. Global disparities of hypertension prevalence and control: a systematic analysis of population-based studies from 90 countries. Circulation. 2016; 134:441-50.

3. Lewington S, Clarke R, Qizilbash N, Peto R, Collins R. Age-specific relevance of usual blood pressure to vascular mortality: a meta-analysis of individual data for one million adults in 61 prospective studies. Lancet. 2002;360:1903-13.

4. Wei Y-C, George NI, Chang C-W, Hicks KA. Assessing sex differences in the risk of cardiovascular disease and mortality per increment in systolic blood pressure: a systematic review and meta-analysis of follow-up studies in the United States. PLoS One. 2017;12:e0170218.

5. World Health Organization. A global brief on hypertension: silent killer, global public health crises (WorldHealthDay2013). Geneva: WHO; 2013. Available: http://apps.who.int/iris/bitstream/10665/ 79059/1/WHO_DCO_ WHD_2013.2_eng.pdf. Document \# WHO/DCO/WHD/2013.2

6. Adeloye D, Basquill C, Aderemi AV, Thompson JY, Obi FA. An estimate of the prevalence of hypertension in Nigeria: a systematic review and metaanalysis. J Hypertens. 2015;33:230-42. https://doi.org/10.1097/HJH. 0000000000000413 PMID:25380154 5

7. Beaglehole R, Bonita R, Alleyne G, Horton R, Li L, Lincoln P, Mbanya JC, McKee M, Moodie R, Nishtar S, Piot P, Reddy KS. Stuckler D; lancet NCD action group. UN high-level meeting on non-communicable diseases: addressing four questions. Lancet. 2011;378:449-55. https://doi.org/10.1016/ S0140-67361160879-9.
8. National Bureau of Statistics. "Nigeria Poverty Profile 2016 Report". Retrieved from: http://www.tucrivers.org/tucpublications/Nigeria\%20Poverty\%20 Profile\%202010.pdf

9. World Health Organisation AFRO, editor. Report of regional director: cardiovascular diseases in the African region: current situation and perspectives. Regional committee for Africa. Maputo: The WHO Regional Office for Africa; 2005.

10. World Bank Nigeria 2013. Available: http://data.worldbank.org/country/nigeria.

11. Akinlua JT, Meakin R, Umar AM, Freemantle N. Current prevalence pattern of hypertension in Nigeria: a systematic review. PLoS One. 2015;10(10): e0140021. https://doi.org/10.1371/journal.pone.0140021.

12. Kayima J, Wanyenze RK, Katamba A, Leontsini E, Nuwaha F. Hypertension awareness, treatment and control in Africa: a systematic review. BMC Cardiovasc Disord. 2013;13:54. https://doi.org/10.1186/1471-226113-54 PMID: 23915151.

13. Ogah OS, Okpechi I, Chukwuonye II, Akinyemi JO, Onwubere BJC, Falase $A O$, Stewart S, Sliwa K. Blood pressure, prevalence of hypertension and hypertension-related complications in Nigerian Africans: a review. World J Cardiol. 2012;4:327-40. https://doi.org/10.4330/wjc.v4.i12.327.

14. Iyer AS, Ahmed MI, Filippatos GS, Ekundayo OJ, Aban IB, Love TE, et al. Uncontrolled hypertension and increased risk for incident heart failure in older adults with hypertension: findings from a propensity-matched prospective population study. J Am Soc Hypertens. 2010:4(1):22-31.

15. Ekpenyong CE, Udokang NE, Akpan EE, Samson TK. Double burden, noncommunicable diseases and risk factors evaluation in sub-Saharan Africa: the Nigerian experience. Eur J Sustain Develop. 2012;1 (2):249-70.

16. Gangwisch JE, Heymsfield SB, Boden-Albala B, et al. Short sleep duration as a risk factor for hypertension analyses of the first national health and nutrition examination survey. Hypertension. 2006;47(5):833-9.

17. Koti A, Roetzheim RG. Patient factors associated with documented provision of JNC 7-recommended hypertension care at an academic family medicine office. J Am Board Fam Med. 2015:28(1):97-104.

18. Thawornchaisit P, de Looze F, Reid CM, Seubsman S, Sleigh A, Team TCS. Health-risk factors and the prevalence of hypertension: cross-sectional findings from a national cohort of 87,143 Thai Open University students. Glob J Health Sci. 2013:5(4):126-41.

19. Kaczorowski J, Chambers LW, Dolovich L, Paterson JM, Karwalajtys T, Gierman T, Farrell B, McDonough B, Thabane L, Tu K, Zagorski B, Goeree R, Levitt CA, Hogg W, Laryea S, Carter MA, Cross D, Sabaldt RJ. Cardiovascular health awareness program (CHAP): a community cluster-randomised trial among elderly Canadians. Prev Med (Baltim). 2008;46(6):537-44. https://doi. org/10.1016/j.ypmed.2008.02.005.

20. Ong KL, Cheung BMY, Man YB, Lau CP, Lam KSL. Prevalence, awareness, treatment and control of hypertension among United States adults 19992004. Hypertension. 2007;49(1):69-75.

21. Barr PJ, Brady SC, Hughes CM, McElnay JC. Public knowledge and perceptions of connected health. J Eval Clin Pract. 2014;20(3):246-54.

22. Cohn ES, Cortés DE, Fix G, Mueller N, Solomon JL, Bokhour BG. Habits and routines in the daily management of hypertension. J Health Psychol. 2012; 17(6):845-55.

23. Chotisiri L, Yamarat K, Taneepanichskul S. Exploring knowledge, attitudes, and practices toward older adults with hypertension in primary care. $J$ Multidiscip Healthc. 2016;9:559-64. https://doi.org/10.2147/JMDH.S112368.

24. World Health Organization. Global health risks: mortality and burden of disease attributable to selected major risks. Global status report on noncommunicable diseases. 2010. Retrieved from https://www.who.int/ nmh/publications/ncd_report_full_en.pdf

25. Gu Q, Dillon CF, Burt VL, Gillum RF. Association of hypertension treatment and control with all-cause and cardiovascular disease mortality among US adults with hypertension. Am J Hypertens. 2010;23(1):38-45.

26. Lee E, Park E. Self-care behavior and related factors in older patients with uncontrolled hypertension. Contemp Nurse. 2017;53(6):607-21. https://doi. org/10.1080/10376178.2017.1368401.

27. Van Dyck D, Plaete J, Cardon G, Crombez G, De Bourdeaudhuij I. Effectiveness of the self-regulation eHealth intervention 'MyPlan1.0.' on physical activity levels of recently retired Belgian adults: a randomized controlled trial. Health Educ Res. 2016;31(5):653-64. https://doi.org/10.1093/ her/cyw036.

28. Mein GK, Shipley MJ, Hillsdon M, et al. Work, retirement and physical activity: cross-sectional analyses from the Whitehall II study. Eur J Public Health. 2005;15(3):317-22. https://doi.org/10.1093/eurpub/cki087. 
29. Lang $\mid A$, Rie $N E$, Wallace $R B$, et al. Smoking cessation and transition into retirement: analyses from the English Longitudinal Study of Ageing. Age Ageing. 2007;36(6):638-43. https://doi.org/10.1093/ageing/afm119.

30. Pennant M, Davenport C, Bayliss S, Greenheld W, Marshall T, Hyde C. Community programs for the prevention of cardiovascular disease: a systematic review. Am J Epidemiol. 2010;172(5):501-16. https://doi.org/10. 1093/aje/kwq171.

31. National population Commission. 2006 population and housing figures: Priority Table, Volume III. Abuja: NPC; 2010. p. 53.

32. Enugu State Government. Internal audit manual. 2010. Retrieved from http://www.sparc-nigeria.com/RC/files/2.2.2_Internal_Audit_Manual_ESG.pdf.

33. Enugu State Ministry of Finance. Pension monthly summary for November 2017. Enugu: Enugu State. Retrieved from https://www.enugustate.gov.ng/ index.php/documental/.

34. Faul F, Erdfelder E, Buchner A, Lang AG. Statistical power analyses using $G^{*}$ power 3.1: tests for correlation and regression analyses. Behav Res Methods. 2009;41(4):1149-60. https://doi.org/10.3758/BRM.41.4.1149.

35. Hickey GL, Grant SW, Dunning J, Siepe M. Statistical primer: sample size and power calculations - why, when and how? Eur J Cardiothorac Surg. 2018;54: 4-9. https://doi.org/10.1093/ejcts/ezy169.

36. Fisher JD, Fisher WA. Theoretical approaches to individual level change in HIV risk behavior. In: Peterson JL, DiClemente RJ, editors. Handbook of HIV prevention. New York: Kluwer Academic/Plenum Press; 2000. p. 3-55.

37. Gazmararian JA, Williams MV, Peel J, Baker DW. Health literacy and knowledge of chronic disease. Patient Educ Couns. 2003;51(3):267-75. https://doi.org/10.1016/S0738-3991(02)00239-2.

38. Poureslami I, Nimmon L, Rootman I, Fitzgerald MJ. Health literacy and chronic disease management: drawing from expert knowledge to set an agenda. Health Promot Int. 2016;32(4):743-54. https://doi.org/10.1093/heapro/daw003.

39. Hackam DG, Quinn RR, Ravani P, et al. The 2013 Canadian hypertension education program recommendations for blood pressure measurement, diagnosis, assessment of risk, prevention, and treatment of hypertension. Can J Cardiol. 2013;29:528-42. https://doi.org/10.1016/j.cjca.2013.01.005.

40. Rodriguez CJ, Swett K, Agarwal SK, et al. Systolic blood pressure levels among adults with hypertension and incident cardiovascular events: the atherosclerosis risk in communities study. JAMA Intern Med. 2014;174(8): 1252-61. https://doi.org/10.1001/jamainternmed.2014.2482.

41. Amine E, Baba N, Belhadj M, et al. Diet, nutrition and the prevention of chronic diseases: report of a joint WHO/FAO expert consultation: World Health Organization; 2002. Retrieved from https://www.who.int/ dietphysicalactivity/publications/trs916/en/gsfao_introduction.pdf

42. de Oliveira Sampaio Y, Araújo MC, Queiroz JDC, et al. Construction of an educational booklet for elderly hypertensive patients: nursing contributions. Int Arch Med. 2016;9(236):1-8. https://doi.org/10.3823/2107 Retrieved from https://imed.pub/ojs/index.php/iam/article/view/1614/1373.

43. Turner RC, Carlson L. Indexes of item-objective congruence for multidimensional items. Int J Test. 2003;3(2):163-71. https://doi.org/10.1207/ S15327574IJT0302-5.

44. Lawshe CH. A quantitative approach to content validity. Pers Psychol. 1975; 28(4):563-75.

45. Heckman JJ, Ichimura H, Todd PE. Matching as an econometric evaluation estimator: evidence from evaluating a job training programme. Rev Econ Stud. 1997;64:605-54.

46. Polit DF, Beck CT, Owen SV. Is the CVI an acceptable indicator of content validity? Appraisal and recommendations. Res Nurs Health. 2007;30(4):45967. https://doi.org/10.1002/nur.20199.

47. Ghazanfari Z, Niknami S, Ghofranipour F, Hajizadeh E, Montazeri A Development and psychometric properties of a belief-based physical activity questionnaire for diabetic patients (PAQ-DP). BMC Med Res Methodol. 2010;10(1):104. https://doi.org/10.1186/1471-2288-10-104.

48. Kaiser HF. An index of factorial simplicity. Psychometrika. 1974;39(1):31-6 Retrieved from https://jaltcue.org/files/articles/Kaiser1974_an_index_of_ factorial_simplicity.pdf.

49. Bartlett MS. A note on the multiplying factors for various chi-square approximations. J Royal stat Soc 16(series B), 1954;296-298.

50. Cattell RB. The scree test for the number of factors. Multivariate Behav Res. 1966;1(2):245-76. https://doi.org/10.1207/s15327906mbr0102_10.

51. Thurstone LL. Multiple factor analysis. Chicago: University of Chicago Press; 1974. p. 535.

52. Landau S, Everitt BS. A handbook of statistical analyses using SPSS. Boca Raton: Chapman \& Hall/CRC; 2004. ISBN: 1-58488-369-3. Retrieved from
http://www.academia.dk/BiologiskAntropologi/Epidemiologi/PDF/SPSS_ Statistical_Analyses_using_SPSS.pdf

53. Chobanian AV, Bakris GL, Black HR, et al. The seventh report of the joint national committee on prevention, detection, evaluation, and treatment of high blood pressure: the JNC 7 report. J Am Med Assoc. 2003;289(19):256071. https://doi.org/10.1001/jama.289.19.2560.

54. The International Physical Activity Questionnaire. Short Last 7 Days SelfAdministered Format 2002 [http://www.ipaq.ki.se].

55. Craig CL, Marshall AL, Sjostrom M, Bauman AE, Booth ML, Ainsworth BE, et al. International physical activity questionnaire: 12 country reliability and validity. Med Sci Sports Exerc. 2003;35(8):1381-95. https://doi.org/10.1249/01. MSS.0000078924.61453.FB.

56. Bauman A, Bull FC, Craig CL, Chey T, Ainsworth BE, Sallis JF, et al. The international prevalence study on physical activity: results from 20 countries. Int J Behav Nutr Phys Act. 2009;6:21. https://doi.org/10.1186/1479-5868-6-21 Retrieved from http://www.ijbnpa.org/content/pdf/1479-5868-6-21.pdf.

57. Oyeyemi AL, Oyeyemi AY, Adegoke BO, Oyetoke FO, Aliyu HN, Aliyu SU, Rufai $A A$. The short international physical activity questionnaire: cross-cultural adaptation, validation and reliability of the Hausa language version in Nigeria. BMC Med Res Methodol. 2011;22(11):156. https://doi.org/10.1186/1471-228811-156 Retrieved from http://www.biomedcentral.com/1471-2288/11/156.

58. Buysse DJ, Reynolds CF 3rd, Monk TH, Berman SR, Kupfer DJ. The Pittsburgh sleep quality index: a new instrument for psychiatric practice and research. Psychiatry Res. 1989;28(2):193-213. https://doi.org/10.1016/0165-1781(89)90047-4.

59. World Health Organization. Global status report on alcohol and health. Geneva: WHO; 2014

60. Bailey RL, Mitchell DC, Miller CK, Still CD, Jensen GL, Tucker KL, SmiciklasWright $\mathrm{H}$. A dietary screening questionnaire identifies dietary patterns in older adults. J Nutr. 2007;137(2):421-6. https://doi.org/10.1093/jn/137.2.421.

61. Morisky DE, Green LW, Levine DM. Concurrent and predictive validity of a selfreported measure of medication adherence. Med Care. 1986;24(1):67-74.

62. Morisky DE, Ang A, Krousel-Wood M, Ward HJ. Predictive validity of a medication adherence measure in an outpatient setting. J Clin Hypertens (Greenwich). 2008; 10(5):348-54. https://doi.org/10.1111/j.1751-7176.2008.07572.x.

63. Culig J, Leppée M. From Morisky to hill-bone; self-reports scales for measuring adherence to medication. Coll Antropol. 2014;38(1):55-62.

64. Sabaté E. Adherence to long-term therapies: evidence for action. Geneva: World Health Organization; 2003.

65. Pickering TG, Miller NH, Ogedegbe G, Krakoff LR, Artinian NT, Goff D. Call to action on use and reimbursement for home blood pressure monitoring: a joint scientific statement from the American Heart Association, American Society of Hypertension, and preventive cardiovascular nurses association. J Cardiovasc Nurs. 2008;23(4):299-323. https://doi.org/10.1161/ HYPERTENSIONAHA.107.189011.

66. George J, MacDonald T. Home blood pressure monitoring. Eur Cardiol. 2015;10(2):95-101. https://doi.org/10.15420/ecr.2015.10.2.95.

67. Arrieta A, Woods JR, Qiao N, et al. Cost-benefit analysis of home blood pressure monitoring in hypertension diagnosis and treatment: an insurer perspective. Hypertension. 2014;64:891-6.

68. Parati G, Stergiou GS, Asmar R, et al. European Society of Hypertension practice guidelines for home blood pressure monitoring. J Hum Hypertens. 2010;24(12):779-85. https://doi.org/10.1038/jhh.2010.54.

69. Hypertension: clinical management of primary hypertension in adults. Retrieved from https://www.nice.org.uk/guidance/cg127.

70. Cohen JW. Statistical power analysis for the behavioural sciences (2nd edn). Hillsdale: Lawrence Erlbaum Associates; 1988.

71. Roopa KS, Rama Devi G. Impact of intervention programme on knowledge, attitude, practices in the management of hypertension among elderly. Stud Home Community Sci. 2014;8(1):11-6. https://doi.org/10.1080/09737189.2014.11885411.

72. Fisher JD, Fisher WA, Williams SS, et al. Empirical tests of an informationmotivation-behavioral skills model of AIDS preventive behavior with gay men and heterosexual university students. Health Psychol. 1994;13(3):238-50.

73. Babaee Beigi MA, Zibaeenezhad MJ, Aghasadeghi K, Jokar A, Shekarforoush $\mathrm{S}$, Khazraei $\mathrm{H}$. The effect of educational programs on hypertension management. Int Cardiovasc Res J. 2014;8(3):94-8.

74. Bilo G, Sala O, Perego C, et al. Impact of cuff positioning on blood pressure measurement accuracy: may a specially designed cuff make a difference? Hypertens Res. 2017;40(6):573-80. https://doi.org/10.1038/hr.2016.184.

75. Celler BG, Argha A, Le PN, Ambikairajah E. Novel methods of testing and calibration of oscillometric blood pressure monitors. PLoS One. 2018;13(8): e0201123. https://doi.org/10.1371/journal.pone.0201123. 
76. Osborn CY, Rivet Amico K, Fisher WA, Egede LE, Fisher JD. An informationmotivation-behavioral skills analysis of diet and exercise behavior in Puerto Ricans with diabetes. J Health Psychol. 2010;15(8):1201-13. https://doi.org/ $10.1177 / 1359105310364173$.

77. DeBate RD, Gatto A, Rafal G. The effects of stigma on determinants of mental health help-seeking behaviors among male college students: an application of the information-motivation-behavioral skills model. Am J Mens Health. 2018;12(5):1286-96. https://doi.org/10.1177/ 1557988318773656

78. Craig P, Cooper C, Gunnell D, et al. Using natural experiments to evaluate population health interventions: new Medical Research Council guidance. J Epidemiol Community Health. 2012;66:1182-6.

79. Dimick JB, Ryan AM. Methods for evaluating changes in health care policy: the difference-in-differences approach. JAMA. 2014;312:2401-2.

80. Tougher S, Dutt V, Pereira S, Haldar K, Shukla V, Singh K, Kumar P, Goodman C, Powell-Jackson T. Effect of a multifaceted social franchising model on quality and coverage of maternal, newborn, and reproductive health-care services in Uttar Pradesh, India: a quasi-experimental study. Lancet Glob Health. 2018;6(2):e211-21. https://doi.org/10.1016/S2214-109X(17)30454-0 Retrieved from https://www.ncbi.nlm.nih.gov/pubmed/29275135.

81. Liddon L, Kingerlee R, Barry JA. Gender differences in preferences for psychological treatment, coping strategies, and triggers to help-seeking. $\mathrm{Br}$ J Clin Psychol. 2018;57:42-58. https://doi.org/10.1111/bjc.12147.

Ready to submit your research? Choose BMC and benefit from:

- fast, convenient online submission

- thorough peer review by experienced researchers in your field

- rapid publication on acceptance

- support for research data, including large and complex data types

- gold Open Access which fosters wider collaboration and increased citations

- maximum visibility for your research: over $100 \mathrm{M}$ website views per year

At $\mathrm{BMC}$, research is always in progress.

Learn more biomedcentral.com/submissions 